\title{
The Research on the Mechanism of Antioxidative and Growth-Promoting Effects of Polyphenols from the Involucres of Castanea Mollissima Blume on IEC-6 Cells Y. XIONG ${ }^{1}$, X. ZHAO ${ }^{1}$, S. DONG ${ }^{1}$, K.J. GUO ${ }^{1, *}$ \\ ${ }^{1}$ College of Animal Science and Technology, Beijing University of Agriculture, No. 7 Beinong Road, Changping District, Beijing 102206, P.R. China
}

${ }^{*}$ Corresponding author

Keywords: IEC-6 cells, Polyphenolic extract from involucres of Castanea mollissima Blume, RT-PCR, Western blotting.

\begin{abstract}
The aim of the paper was to study the effects of Polyphenolic extract from involucres of Castanea mollissima Blume (PICB) on IEC-6 cell proliferation and growth and antioxidant status. The IEC-6 heat stress model was established and IEC-6 cells of control group and heat stress group were treated with $80 \mu \mathrm{g} / \mathrm{ml}$ PICB. HSP70 ODC EGF, EGFR, SOD mRNA transcription and protein expression of IEC-6 cells were detected using RT-PCR and Western blot. The results showed that PICB concentrations had no significant effect $(\mathrm{P}>0.05)$ on mRNA and protein expression of IEC-6 in normal temperature. Under heat stress conditions, HSP70, ODC, EGF, EGFR, SOD mRNA transcription and protein expression of PICB group were higher than the control group $(\mathrm{P}<0.05)$. In conclusion, PICB could up-regulate HSP70, ODC, EGF, EGFR, SOD mRNA and protein expression of heat stressed IEC-6 cell, showing the mechanism of its anti-oxidative and growth-promoting function.
\end{abstract}

\section{Introduction}

Heat stress could induce oxidative stress in animals, making animal produce lipid peroxidation and change enzyme activity, eventually leading to oxidative damage and low performance. How to effectively alleviate heat stress response of livestock caused by summer hot temperatures is a big problem faced by modern livestock production.

Studies showed that extracts from chestnut involucres, flowers, leaves and seeds have antioxidant properties [1]. Li et al. [2] reported Polyphenolic extract from involucres of Castanea mollissima Blume (PICB) had a strong scavenging ability of free radicals. Our previous studies showed: PICB had strong radical scavenging and antioxidant capacity on IEC-6 cultured in vitro [3]. Broilers feeding trials showed that PICB improved significantly the growth performance and anti-oxidative capacity under heat stress conditions [4]. This study is to further investigation the effects of PICB on ODC, EGF, EGFR, SOD, HSP70 mRNA transcription and protein expression of in vitro cultured IEC - 6 cells under normal temperature and heat stress condition. 


\section{Materials and Methods}

\section{Materials}

IEC-6 cell line (CRL21592): purchased from China Xiehe Medical University of science and technology cell preservation room. Involucre of Castanea mollissima: purchased from huairou Castanea mollissima experimental sites. PICB was obtained according to Shi et al. [3], polyphenolic content of PICB was $86.54 \%$.

\section{Methods}

HSP70, ODC, EGF, EGFR, SOD mRNA Transcription of IEC-6 Measured by Real Time-PCR. IEC-6 cell heat stress model was described by Guo et al. [5] and PICB level was set as $80 \mu \mathrm{g} / \mathrm{ml}$ [6]. The IEC-6 cells were divided into the control group (normal temperature I and high temperature III) and PICB group (normal temperature II, high temperature IV). After adjusting the cell concentration of $1 \times 10^{5}$ cell $/ \mathrm{mL}$, the cells were transplanted into $25 \mathrm{~cm}^{2}$ cell culture flasks and cultured at $37^{\circ} \mathrm{C}, 5 \% \mathrm{CO} 2$ incubator for $24 \mathrm{~h}$. At the end of incubator, total RNA of IEC-6 cell were extracted using Trizol method and RNA concentration and purity were measured by nucleic acid detector. RNA ranging within OD260/OD280=1.9 2.1 was used for reverse transcription to generate cDNA template. Primers were designed by primer 5.0 software (table 1). HSP70, ODC, EGF and EGFR, SOD mRNA transcription levels were determined by RT-PCR. The error bars given represented the standard deviation of the CT values.

Table 1 Primer set for RT-PCR

\begin{tabular}{|c|c|c|c|}
\hline Gene & Primer sequences & Product length & $\begin{array}{l}\text { Annealing } \\
\text { temperature }\end{array}$ \\
\hline \multirow[t]{2}{*}{ EGF } & F:5'-GCCACGGTTACATTCACT-3' & $152 b p$ & $60^{\circ} \mathrm{C}$ \\
\hline & R:5'-TATCCAAATCGCCTTCTC-3' & & \\
\hline \multirow[t]{2}{*}{ EGFR } & F:5'-AAGGCACAAGTAACAGGCTCA-3' & $110 \mathrm{bp}$ & $62^{\circ} \mathrm{C}$ \\
\hline & R:5'-GGTGATTTCCAAGTTTCCAAG-3' & & \\
\hline \multirow[t]{2}{*}{ ODC } & F:5'-GGGACAGGATTTGATTGTGC-3' & $188 \mathrm{bp}$ & $59^{\circ} \mathrm{C}$ \\
\hline & R:5'-TGTGCTCTGGCAACTTTCAT-3' & & \\
\hline \multirow[t]{2}{*}{ SOD } & F:5'-AGGTCGCTTACAGATTGCC-3' & $170 \mathrm{bp}$ & $58^{\circ} \mathrm{C}$ \\
\hline & R:5'-CATTCTCCCAGTTGATTACATT-3' & & \\
\hline \multirow[t]{2}{*}{ HSP70 } & F:5'-ATGCTTCAGACCTCCCTT-3' & $192 b p$ & $59^{\circ} \mathrm{C}$ \\
\hline & R:5'-CTCCACCAACTATCTCCACT-3' & & \\
\hline$\beta$ & F:5'-TGTCACCAACTGGGACGATA-3' & $165 b p$ & $60^{\circ} \mathrm{C}$ \\
\hline -Actin & R:5'-GGGGTGTTGAAGGTCTCAAA-3' & & \\
\hline
\end{tabular}

ODC, EGFR, SOD Protein Expression Levels in IEC-6 Cells Detected by Western Blotting. The trial design was as same as 2.1. Pre-prepared EGF activating solution was added to the cell culture flasks $10 \mathrm{~min}$ before the end of incubation. Cell membrane and cytoplasm proteins were extracted. Cell concentration was detected by BCA kit to calculate the volume of the protein solution required to obtain $80 \mu \mathrm{g}$ proteins in sample. Then $5 \times$ loading buffer was added into the solution, which were heated in boiling water for 5-10 min. Successively, 12\% SOD or ODC or 10\% EGFR 
separation gel and 5\% concentrated gel were used to carry out sodium dodecyl sulfate - polyacrylamide gel electrophoresis (SDS-PAGE). The separated proteins were transferred to PVDF membranes at $300 \mathrm{~mA}$ for $70 \mathrm{~min}$. Then the membranes were incubated at $5 \%$ skimmed milk powder for $1 \mathrm{~h}$. The primary antibody were added and kept overnight, membranes were washed. The secondary antibody were added and incubated for $2 \mathrm{~h}$. The membranes were developed to detect the ODC, SOD, EGFR protein expression using Image $\mathrm{J} 2 \mathrm{x}$ analysis software.

\section{Statistical Analysis}

The dataset was analyzed by One-way ANOVA of SPSS17.0 and significant differences were set as $\mathrm{P}<0.05$ tested using Turkey's multiple comparison method. The results were expressed as mean \pm standard error $(X \pm S)$.

\section{Results}

\section{Effects of PICB on HSP70 mRNA Transcription of IEC-6 cell}

HSP70 mRNA transcriptions of IEC-6 cell were shown in Fig. 1. Under normal temperature, HSP70 mRNA transcriptions of group I and II were at the same level (P> 0.05); Under heat stressed condition, HSP70 mRNA transcription of group IV was significantly higher than that of group III $(\mathrm{P}<0.05)$; HSP70 mRNA transcription of group III was significantly lower than those of groups I, II and IV $(\mathrm{P}<0.05)$.

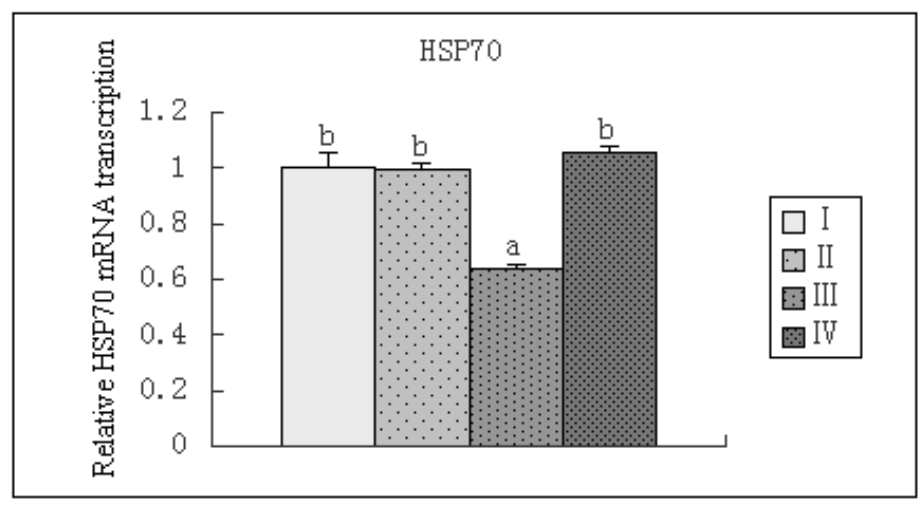

Figure 1. Effects of PICB on relative HSP70 mRNA transcription of IEC-6. PICB: Polyphenolic extract from involucres of Castanea mollissima Blume; I: control group under normal temperature; II: control group under normal temperature; III: PICB treated group under normal temperature; IV: PICB treated group under heat stress condition.

\section{Effect of PICB on EGF, EGFR, ODC, SOD mRNA Transcriptions of IEC-6 Cells}

Fig. 2 showed EGF, EGFR, ODC, SOD mRNA transcriptions of IEC-6 cells. Under normal temperature, mRNA transcription of EGF in group I and group II had no significant differences. Under heat stress condition, EGR mRNA transcription of group IV was significantly higher than that of group III $(\mathrm{P}<0.05)$ and had no significant differences with those of group I and II. EGFR mRNA transcriptions of PICB treated groups were higher than those of control groups $(\mathrm{P}<0.05)$ both under normal temperature condition and under heat stress condition. There was no 
significant difference between group IV and group I. The similar situation was for the ODC mRNA transcription, except that there was no significant difference between group IV and II. The situation for SOD mRNA transcription of was same as EGFR.

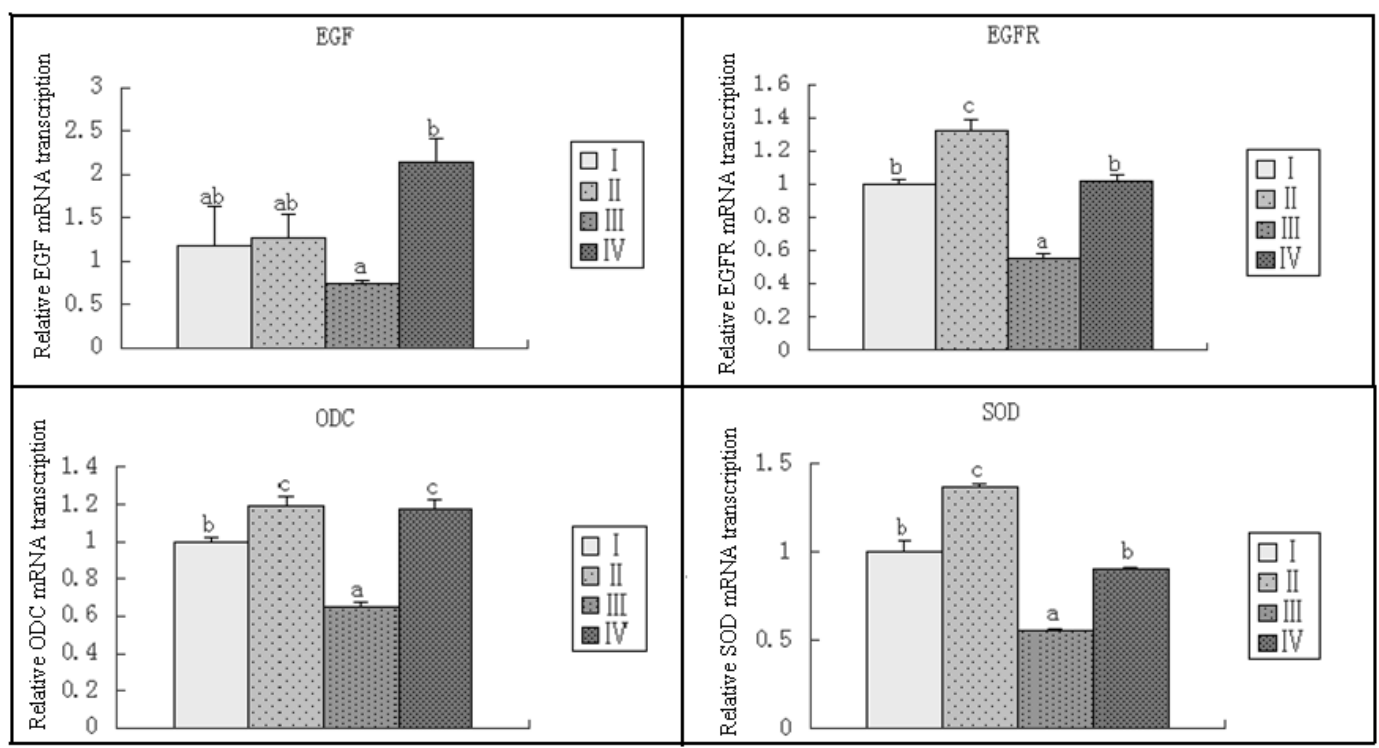

Figure 2. Effects of PICB on mRNA transcription of some genes of IEC-6 (abbreviation see Fig.1).

\section{Effects of PICB on EGFR, ODC, SOD Protein Expression of IEC-6}

The results of western blotting showed EGFR protein had 170KDa, ODC protein $51 \mathrm{KDa}$ and SOD protein $25 \mathrm{KDa}$ (see Fig. 3). Under normal temperature, EGFR protein expressions were at the same level. EGFR protein expression of group IV was significantly higher than that of group III and had no difference with those of group I and II. The similar situation was for ODC protein expressions. Both under normal temperature and heat stress condition, SOD protein expressions of PICB treated groups were significantly higher than those of normal temperature groups $(\mathrm{P}<0.05)$. SOD protein expression of group II was significantly highest among the groups $(\mathrm{P}<0.05)$ and there was no significant difference between group I and IV.

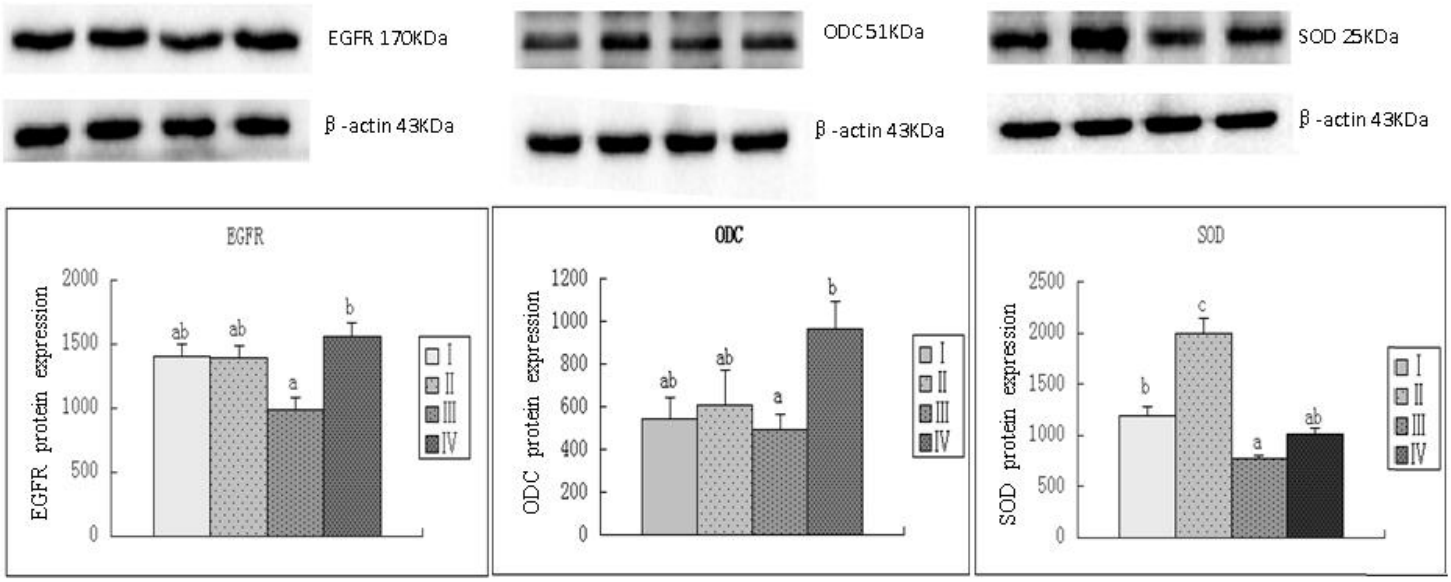

Figure 3. Effects of PICB on the protein expression of some genes in IEC-6 (abbreviation see Fig.1). 


\section{Discussions}

\section{The Effect of PICB on HSP70 mRNA Transcription}

Highly conserved heat shock protein HSP70 played an important role in protein synthesis, molecular transport through membrane, signal transmission and the formation and maintenance of protein spatial structure [7]. Chen et al. [8] found that HSP70 mRNA transcription increased significantly in pig tissue when added anti-stress traditional Chinese medicine infusion, which protected rats from heat stress damage and improve tolerance. This study showed that PICB addition could improve HSP70 mRNA transcription in heat stress condition till the normal temperature level, which implied PICB could mitigate the effect of heat stress.

\section{Effects of PICB on Growth-related Genes' mRNA Transcription and Protein Expression of IEC-6}

EGF had the functions of promoting epithelial cell proliferation, regulating protein synthesis, improving the construction of collagen and accelerating wound healing [9]. EGFR plays an important role in maintaining cell growth and proliferation after injured [10]. ODC was a key rate-limiting enzyme of polyamine biosynthesis, which is responsible for growth [11]. This study showed that PICB up-regulated the EGF, EGFR and ODC mRNA transcriptions and EGFR and ODC protein expressions under heat stress comparing the control group, which implied PICB could promote cells proliferation and strengthen intestinal mucosal repair after damaged.

\section{Effects of PICB on Anti-oxidative Capacity}

SOD's vitality level indirectly reflects the free radical scavenging ability [12]. Research showed Curcumin could enhance SOD expression of rat intestinal mucosa tissue significantly, thus improve the ability of removing oxygen free radicals to protect rat intestinal [13]. This study resulted that PICB could improve SOD mRNA transcription and protein expression under normal and heat stress temperature, which are in accordance to Dong et al.[6].

\section{Conclusions}

PICB up-regulated the mRNA transcription of HSP70, EGF, EFGR, ODC and SOD of IEC-6, leading to the up-regulation of protein expression represented by those of EGFR, ODC and SOD. This study revealed the mechanism of the anti-oxidant and growth promoting function of PICB on IEC-6, which provided the theoretic basis for the application of PICB in animal husbandry practice.

\section{Acknowledgement}

This research was financially supported by the Project of the Importation and Development of High-Caliber Talents Project of Beijing Municipal Institutions (CIT\&TCD201304093) and the agricultural technology project of Beijing Municipal Commission of Rural Affairs: the importation and dissemination of feed and water saving precise feeding technology for dairy cattle (20150125). 


\section{References}

[1] J. C. M. Barreira, C. F. R. Ferreire, M. B. P. P. Oliveira, J. A. Pereira. Antioxidant activities of the extracts from chestnut flower, leaf, skins and fruit. Food Chem. 107 (2008) 1106-1113

[2] J. F. Li, Y. Q. Duan, H. L. Ma, H. H. Zhang, F. F. Xu, L. R. Huang. 2010. Extraction of polyphenols from chestnut shells and study on in vitro antioxidant activities. Wood chem. indust. 2(2010)53-58.

[3] E. H. Shi, H. Li, M. C. Gu, C. X. Jia, K. J. Guo. Chinese chestnut involucre polyphenols purification process optimization and its effects on cell vitality. Chin. Food Sci. 13 (2013):134-140. In Chinese

[4] H. Li, S. Dong, Y. Xiong, M. C. Gu, K. J. Guo. Effect of Chestnut Involucres Polyphenols on Growth Performance and Antioxidant Properties of AA Broilers. Chin. Agri. Sci. 4 (2015): 788-795. In Chinese

[5] K. J. Guo, S. F. Xu, P. Yin, W. Wang, X. Z. Song, F. H. Liu, J. Q. Xu, I. Zoccarato. Active components of common traditional Chinese medicine decoctions have antioxidant functions. J. Ani. Sci. 89(2011) 3107-3115.

[6] S. Dong, H. Li, L. Gasco, Y. Xiong, K. J. Guo, I. Zoccarato. Antioxidative activity of the polyphenols from the involucres of Castanea mollissima Blume and their mitigating effects on heat stress. Poult. Sci. 5(2015)1096-1104.

[7] W. J. Cheng, Q. L. Li, Y. M. Sun, H. M. Wang, J. B. Li, J. F. Zhong. Heat shock protein (HSP70) advances. J. Ani. husbandry \& vet. med. 27 (2008)55-57. In Chinese

[8] Q. Chen, X. G. Hua, X. F. Gu, W. W. Sheng, L. Cui, F. M. Jiang. Chinese Herbs on the expression of heat shock protein HSP70 mRNA in rat. Journal of Shanghai Jiaotong University (Agricultural Science). 24 (2006)61-64. In Chinese

[9] D. Song, X. B. Fang, Progress of epidermal growth factor. 2002. Progress of Anatomical Sciences. 8 (2002) 339-42.

[10] A. S. Tarnawski, M. Tomikawa, M. Ohta, I. J. Sarfeh. Antacid talcid activates in gastric mucosa genes encoding for EGF and its receptor. The molecular basis for its ulcer healing action. J. Physiol. Paris. 94(2000)93-98.

[11] Z. L. Zhang, W. W. Chen. Astragalus injection through activating ornithine decarboxylase promotes the differentiation of IEC-6 cells research. Chinese and Western Medicine. 22 (2002)439-443. In Chinese

[12] L. Dong, Y. Z. He, Y. L. Wang, Z. Y. Dong. Superoxide dismutase (SOD) application research progress. J. Agri. Sci. \& Tech. 15 (2013) 53-58. In Chinese

[13] W. B. Song, Z. S. Zhang, B. Xiao, M. L. Huang, S. Y. Zhao, X. Y. Wang. Curcumin on MPO and SOD of enteritis of rats effect. Modern digestive and intervention. 13 (2008) 14-17. 